\title{
Effect of Scratch Velocity on Deformation Features of C-plane Sapphire during Nanoscratching
}

\author{
Pingfa Feng - Chenglong Zhang* - Zhijun Wu - Jianfu Zhang \\ Tsinghua University, Department of Mechanical Engineering, The State Key Laboratory of Tribology, China
}

\begin{abstract}
The effects of scratch velocity on plastic and brittle deformation features of (0001) C-plane sapphire were studied in nanoscratch tests. The test was conducted under a ramping loading condition from $40 \mu \mathrm{N}$ to $200 \mathrm{mN}$ using a nanomechanical test system. A Berkovich nanoindenter was employed in this study. The scratch velocities were set at 2, 4, 8, and $16 \mu \mathrm{m} / \mathrm{s}$. Plastic and brittle deformation features were observed by scanning electron microscopy. The residual stress features of the deformation zones in the scratch groove were observed by Raman spectroscopy. Comparative studies of surface depth profiles and scratch groove features obtained with different scratch velocities reveal that the scratch velocities have distinct effects on the deformation features of C-plane sapphire.
\end{abstract}

Keywords: (0001) C-plane sapphire, nano-scratch test, scratch velocity, plastic deformation, brittle deformation, residual stress

\section{O INTRODUCTION}

As a good wave-transparent material, sapphire crystals have been used in many fields, such as highspeed integrated-circuit chips, laser substrates, etc., due to their inherent characteristics [1] to [5]. The processed surface quality of the sapphire substrate has a strong influence on the application performance of sapphire elements. Moreover, the cost of precision and ultra-precision processing of the fine surface during sapphire manufacturing for optoelectronic applications is high [6] to [9]. Therefore, an investigation into the material removal features and deformation behaviours of sapphire is necessary and can be applied to guide the sapphire manufacturing process.

The removal modes of brittle materials affect the quality of the surface processed under conventional machining conditions. Brittle fracture removal and plastic deformation removal are regarded as the two main material removal modes in the processing of brittle materials [10] to [16]. The brittle fracture removal mode has a negative effect on the processed workpiece surface and leads to a lower quality of the processed surface. Under suitable processing conditions the plastic deformation removal mode can be achieved, resulting in adequate surface quality. The scratch test, regarded as a process analogous to the machining of materials, has been employed to study the deformation behavior and tribological properties of materials [17] to [21]. The deformation patterns induced in the scratch process provide preliminary information needed to determine the material removal behaviour.

According to the removal modes of the materials mentioned in the previous section, it can be demonstrated that a smooth scratch groove can be produced in a completely plastic mode with low depth of cut (DOC) scratching, thus helping to eliminate brittle fracture features, such as cracks and chipping dents, in brittle materials, as also reported in the literature [22] to [24]. The nanoscratch tests available for scratch experiments carried out under extremely low DOC can be employed to reveal the plastic and brittle deformation features of brittle materials.

In this paper, the nanoscratch tests were carried out to reveal the removal properties and deformation behaviors of (0001) C-plane sapphire. The effects of scratch velocities on plastic and brittle deformation features were studied. Scanning electron microscopy (SEM) was employed to observe the deformation features. Residual stress features of the deformation zones in the scratch grooves were studied by Raman spectroscopy. Comparative studies of the surface depth profiles and scratch groove features induced by different scratch velocities are presented.

\section{EXPERIMENTAL PROCEDURE}

Scratch experiments were conducted on a nanomechanical test system (Nano Indenter G200, Agilent Corp., USA) in scratch mode. The size of the sapphire sample was $15 \times 10 \times 1 \mathrm{~mm}$. C-plane (0001) sapphire that is suitable for infrared detector applications was selected for use in this study. A diamond Berkovich nanoindenter tip was employed. The scratch velocities were set at 2, 4, 8, and 16 $\mu \mathrm{m} / \mathrm{s}$. The scratching track was set at $300 \mu \mathrm{m}$ in all tests. The applied normal load was increased linearly from $40 \mu \mathrm{N}$ to $200 \mathrm{mN}$ along the scratch length. The process for a standard scratch is shown in Fig. 1.

First, a pre-scan was carried out in order to measure the initial surface property of the C-plane 
sapphire sample under a low load of $40 \mu \mathrm{N}$. Then, the indenter penetrated into the sapphire workpiece with the pre-set loading characteristics. Finally, the residual deformation feature was recorded by scanning the scratch groove again (post-scan) under a $40 \mu \mathrm{N}$ load. Penetration depth and residual deformation data were also collected during the test, which can be used in quantitative analysis of the deformation features of the sapphire workpiece.

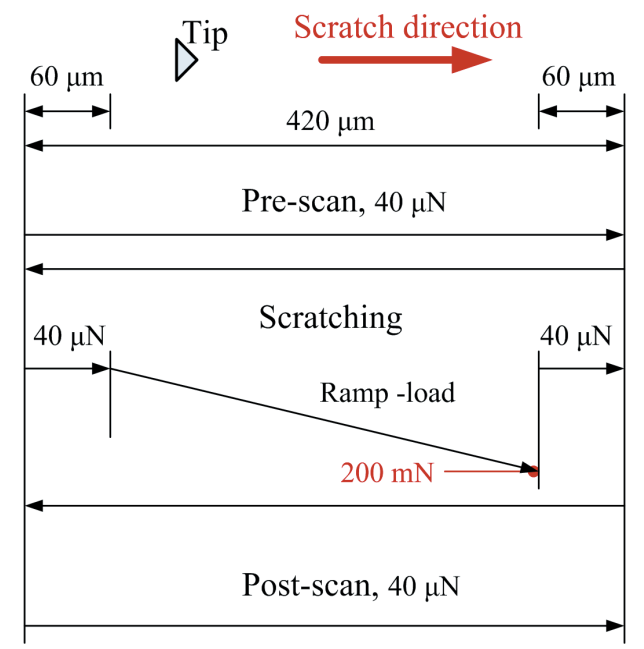

Fig. 1. Schematic diagram of the scratching

The sapphire sample was ultrasonically cleaned in acetone for $15 \mathrm{~min}$. The morphologies of the cleaned scratch grooves were then observed by SEM (Quanta 200 FEG, FEI Corp., Netherlands). Raman spectroscopy (LabRAM HR800, HORIBA Jobin Yvon S.A.S., France) was employed to reveal the residual stress features of the deformation zones in the scratch groove. The Raman spectrometer included an Ar+ laser $(514 \mathrm{~nm})$ to excite the specimen. A maximum laser power of $20 \mathrm{~mW}$ was used. Raman spectra were collected within and outside the scratch groove at room temperature to compare the residual stress distribution features of the sapphire sample.

\section{EXPERIMENTAL RESULTS AND DISCUSSION}

\subsection{Analysis of Scratch Profiles}

Fig. 2 presents the scratch profiles made with the diamond Berkovich nanoindenter tip at scratch velocities of a) 2 , b) 4 , c) 8 , and d) $16 \mu \mathrm{m} / \mathrm{s}$. The pre-scan curves show the unscratched surface of the sapphire workpiece. The penetration depth profiles (scratching) reveal the real-time deformation behaviours of the sapphire sample. The post- scan curves indicate the removal features of the sapphire workpiece induced by the scratching. Negative scratch depth means the indenter is located below the initial position of the workpiece surface, and positive depth indicates the indenter is moved above the initial surface by the scattered debris produced during the scratch test.

The pre-scan profiles in Fig. 2 indicate that the surface of the prepared sapphire sample is smooth. The profiles also show very small elastic-plastic deformations (Figs. 2a and b), which might have been caused by the pre-scan load $(40 \mu \mathrm{N})$ as the scratch velocity is relatively low. With the increase in the applied load, there is no visible fluctuation in the scratching profile, implying that the deformation of the sapphire sample is a completely elastic-plastic deformation under this loading condition. When the load reaches a certain value, the scratch depth abruptly increases. This load is termed the "critical load" (Fc), and the depth is termed the "critical depth" (Dc); these critical values are usually used to study the ductile-brittle transition characteristics of the material removal. The critical load and critical depth were then determined from Fig. 2 and nanoscratch data were collected: these are presented in Table 1.

By comparing the collected curves, it can be observed that there are three distinct deformation stages during the scratch processing. In the first stage, the scratching and post-scan profiles are almost smooth, which is clearly visible in Figs. $2 \mathrm{c}$ and $\mathrm{d}$ but not obvious in Figs. 2a and b. This indicates that the deformation of the sapphire sample is completely elastic-plastic for the c) 8 and d) $16 \mu \mathrm{m} / \mathrm{s} \mathrm{scratch}$ velocities, but the material is removed in plastic mode and leaves fish-bone-like traces for the a) 2 and b) 4 $\mu \mathrm{m} / \mathrm{s}$ scratch velocities.

In the second stage, the scratching depthdisplacement curves show small waves, while the post-scan depth-displacement curves show fluctuations. This implies that microcracks and severe fish-bone features are produced during the scratching.

In the third stage, abrupt changes and larger waves in the scratching and post-scan curves appeared, which means that larger microcracks and chipping dents emerge within the grooves and the material is thus removed by brittle deformation. The starting positions of the abrupt changes and larger fluctuations differ for the a) 2, b) 4, c), and d) $16 \mu \mathrm{m} / \mathrm{s}$ scratch velocities in Fig. 2, indicating that the critical loads and critical depths differ for different scratch velocities.

Therefore, as the load increases the material removal of sapphire during scratch processing is 

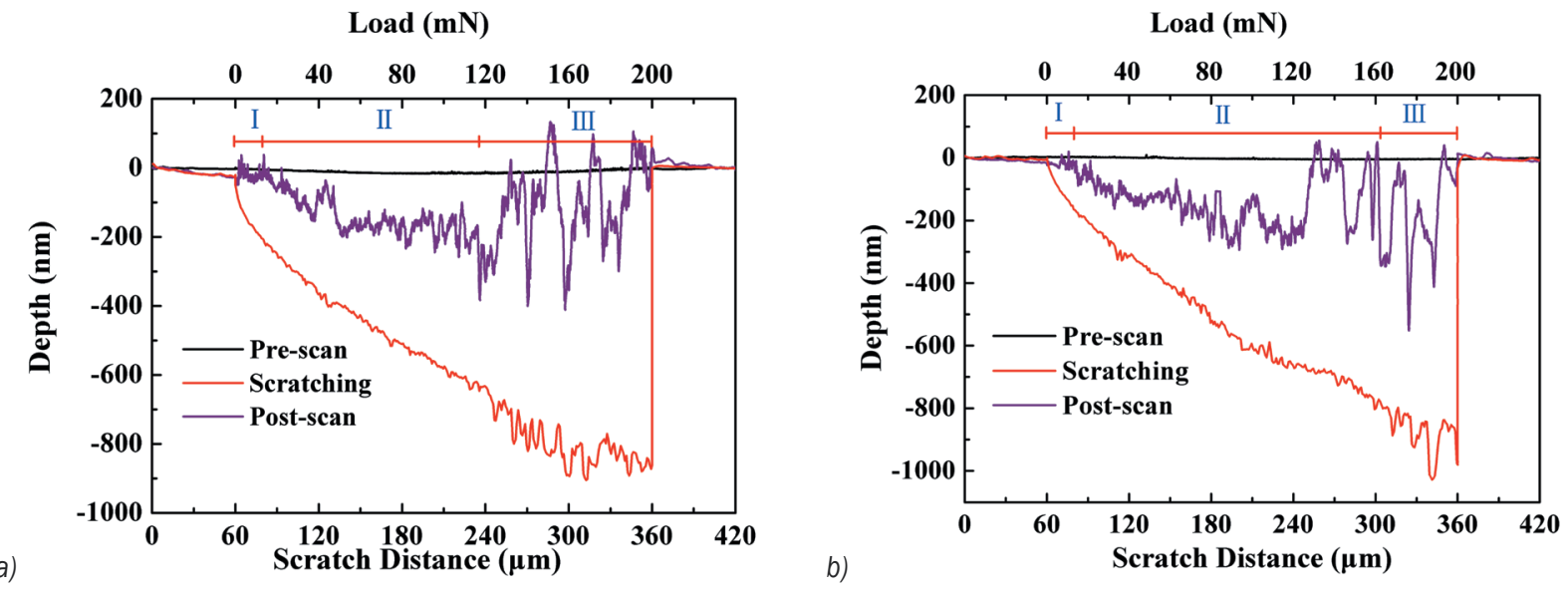

\section{Load (mN)}
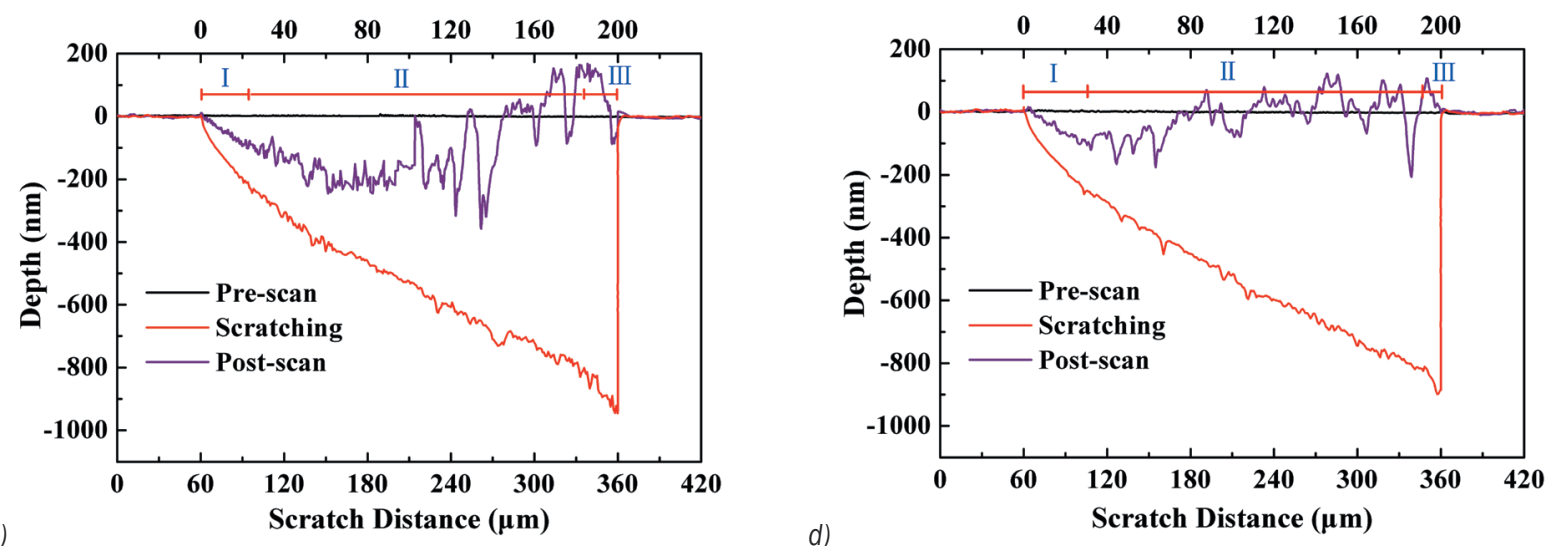

Fig. 2. Surface depth profiles for scratch velocities of a) 2 , b) 4 , c) 8 , and d) $16 \mu \mathrm{m} / \mathrm{s}$ under loading conditions ramping to a maximum of $200 \mathrm{mN}$

described as elastic-plastic deformation, plastic deformation with the generation of severe fish-bone features, and brittle deformation at the highest load.

The load and depth ranges for each scratch velocity in the three stages are given in Table 1.

Table 1. Load ranges and critical depth for each scratch velocity

\begin{tabular}{cccccc}
\hline $\begin{array}{c}\text { Scratch } \\
\text { velocity } \\
{[\mu \mathrm{m} / \mathrm{s}]}\end{array}$ & $\begin{array}{c}\text { Stage I } \\
\text { [mN] }\end{array}$ & $\begin{array}{c}\text { Stage II } \\
\text { [mN] }\end{array}$ & $\begin{array}{c}\text { Stage III } \\
\text { [mN] }\end{array}$ & $\begin{array}{c}F_{c} \\
{[\mathrm{mN}]}\end{array}$ & $\begin{array}{c}D_{c} \\
{[\mathrm{mN}]}\end{array}$ \\
\hline 2 & 0 to 12 & 12 to 120 & 120 to 200 & 120 & 630 \\
\hline 4 & 0 to 15 & 15 to 165 & 165 to 200 & 165 & 790 \\
\hline 8 & 0 to 25 & 25 to 180 & 180 to 200 & 180 & 805 \\
\hline 16 & 0 to -30 & 30 to 190 & 190 to 200 & 190 & 810 \\
\hline
\end{tabular}

Table 1 shows that the critical load is 120,165 , 180 , and $190 \mathrm{mN}$ and the critical depth is 630,790 , 805 , and $810 \mathrm{~nm}$ for scratch velocities of a) 2 , b) 4 , c) 8 , and d) $16 \mu \mathrm{m} / \mathrm{s}$, respectively. It can be observed that $\mathrm{Fc}$ and Dc increase with scratch velocity. This trend shows that higher scratch velocity can lead to a higher proportion of plastic deformation and results in better surface quality of the workpiece.

\subsection{Morphology Features of the Scratch Grooves}

To compare the distinct scratch regions, the scratch process was divided into four parts according to the applied load. Figs. 3a) to d are SEM micrographs of the scratch groove obtained with a scratch velocity of $2 \mu \mathrm{m} / \mathrm{s}$.

In the low load stage, a smooth groove appeared with small plastic pile-ups and ironing lines within the groove (see Figs. 1a and 3a), implying a complete elastic-plastic deformation. With an increase in the normal load, the groove becomes broader and microcracks, chipping dents, and slip lines are observed. As the load increases to approximately 80 $\mathrm{mN}$, microcracks are generated around the scratch 
and fish-bone traces and stick-slip lines emerge in the scratch, as shown in Fig. 3b.
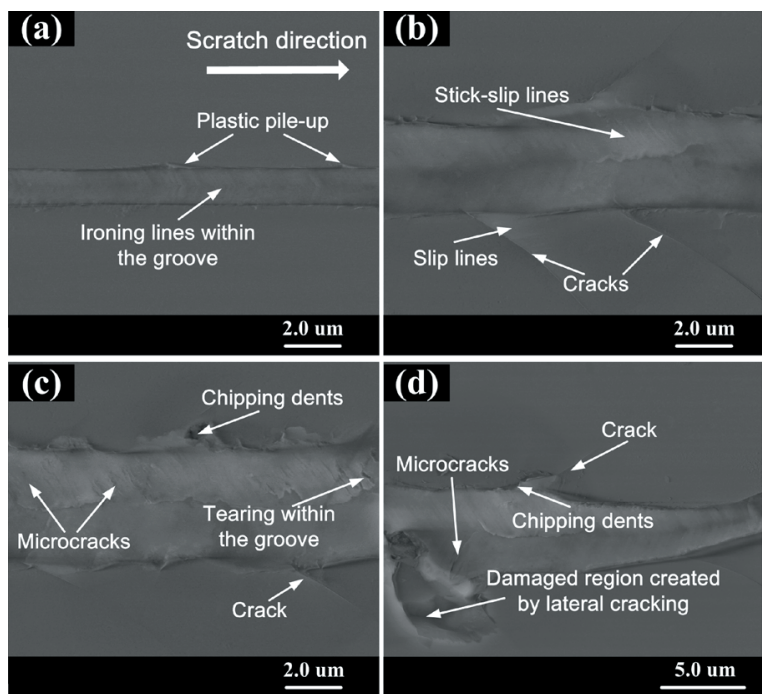

Fig. 3. Micrographs of deformation features induced under a scratch velocity of $2 \mu \mathrm{m} / \mathrm{s}$
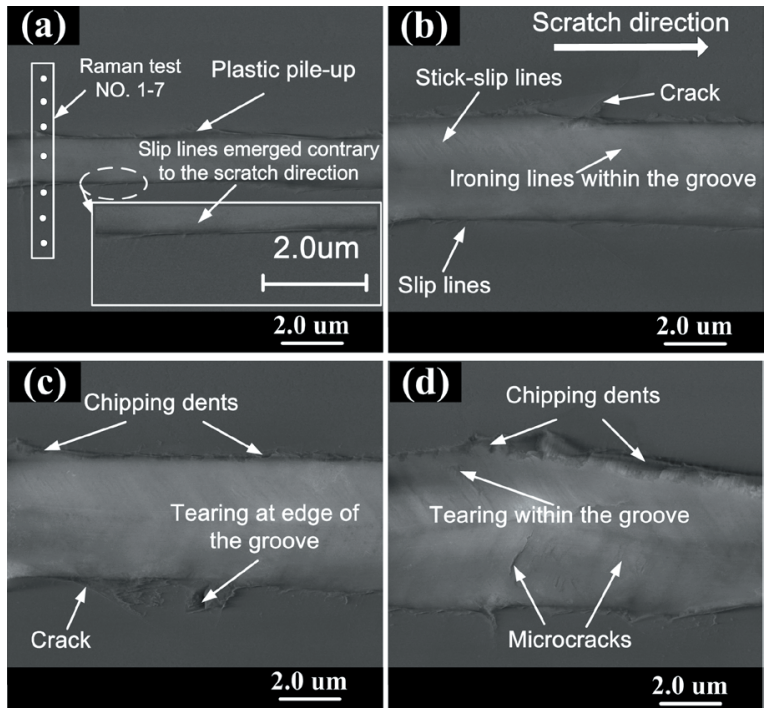

Fig. 4. SEM morphology of deformation features induced with a scratch velocity of $16 \mu \mathrm{m} / \mathrm{s}$

Chipping dents around the scratch and tearing regions within the groove are observed as the applied load reaches about $120 \mathrm{mN}$, as shown in Fig. 3c. Owing to the increase in the applied load and the induced load, microcracks along the scratch direction within the groove are also seen. The emergence of chipping dents indicates that brittle fracture of the C-plane sapphire occurred when the applied normal load was $120 \mathrm{mN}$ with a scratch velocity of $2 \mu \mathrm{m} / \mathrm{s}$. When the normal load increases to approximately 200
$\mathrm{mN}$, the damaged regions induced by the microcracks extension appear and brittle fracture removal features are clearly observed, as shown in Fig. 3d. Therefore, the material removal of the C-plane sapphire induced at a scratch velocity of $2 \mu \mathrm{m} / \mathrm{s}$ is a combination of plastic deformation and brittle fracture.

Fig. 4 shows SEM micrographs of deformation features induced with a scratch velocity of $16 \mu \mathrm{m} / \mathrm{s}$. The deformation features of the scratch groove obviously differ from the features induced with a scratch velocity of $2 \mu \mathrm{m} / \mathrm{s}$ (as shown in Fig. 3). Plastic pile-up is seen around the groove when the applied load is low, as shown in Fig. 4a, indicating that elastic-plastic deformation occurred during this scratch process. Moreover, the slip lines clearly show scattering from the scratch groove (shown in the white elliptical region and the magnified image in the white rectangular region in Fig. 4a), but are not visible when the scratch velocity is $2 \mu \mathrm{m} / \mathrm{s}$ (as shown in Fig. 3a).

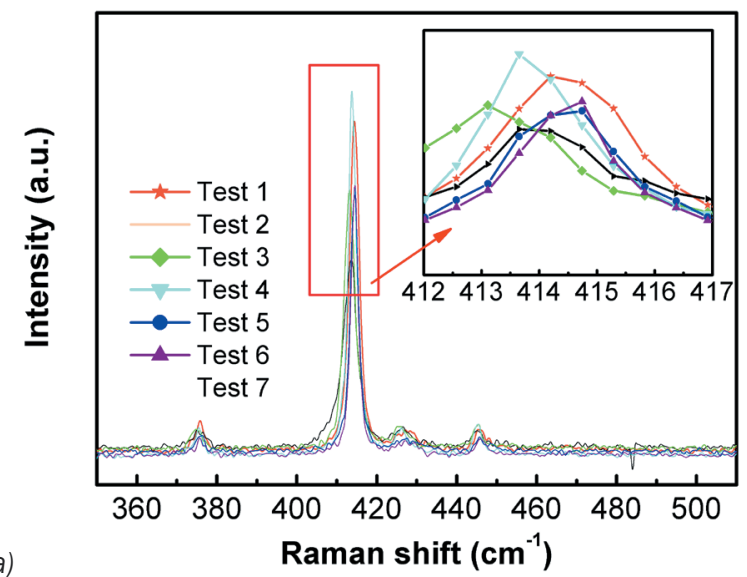

a)

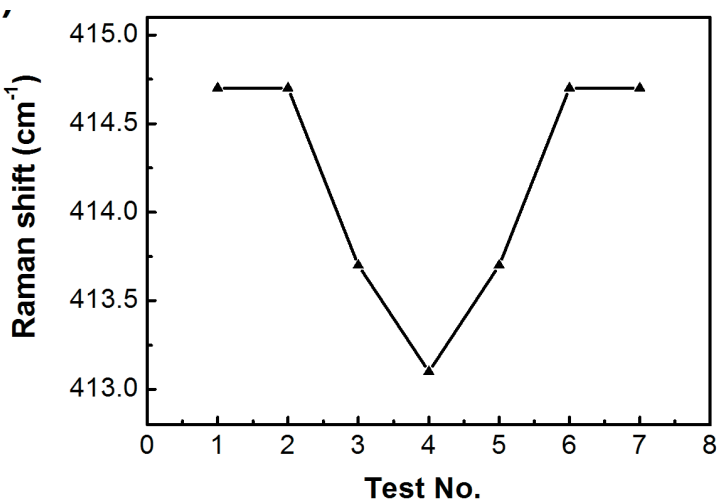

Fig. 5. Raman spectra and Raman shift within and outside the groove; a) Raman spectra, b) Raman peak positions

Other researchers have reported that the observed plastic deformation features of scratch processing, i.e. pile-up and microcracks, result from the tensile 
stress field [24] and [25]. To clarify the material removal mechanism of sapphires, particularly for plastic deformation, Raman spectroscopy was applied to measure the stress characteristics of the scratch groove resulting from a constant scratch velocity of $16 \mu \mathrm{m} / \mathrm{s}$, as shown in Fig. 5. The Raman peaks measured in the groove were at lower wave numbers than those measured in the undeformed area of the sapphire workpiece (see Figs. 4a and 5a). The Raman peaks' shift to lower wave numbers indicates the generation of tensile stress within the scratch groove [25]. Therefore, it can be concluded that tensile stress appears within the scratch groove during scratching. Tensile stress is the fundamental factor causing the stacking faults, location loops, and dislocation glide that are observed during the plastic deformation mechanisms of sapphire in a nanoscratch.

With the increase in scratch load, microcracks, tears, and chipping dents are observed in and around the scratch groove at a scratch velocity of $16 \mu \mathrm{m} / \mathrm{s}$. However, no brittle fracture region can be observed when the scratch velocity is $16 \mu \mathrm{m} / \mathrm{s}$. The deformation features of the maximum load (approximately 200 $\mathrm{mN}$ ) induced at scratch velocities of 4 and $8 \mu \mathrm{m} / \mathrm{s}$ are also observed and compared in this study, as shown in Fig. 6.
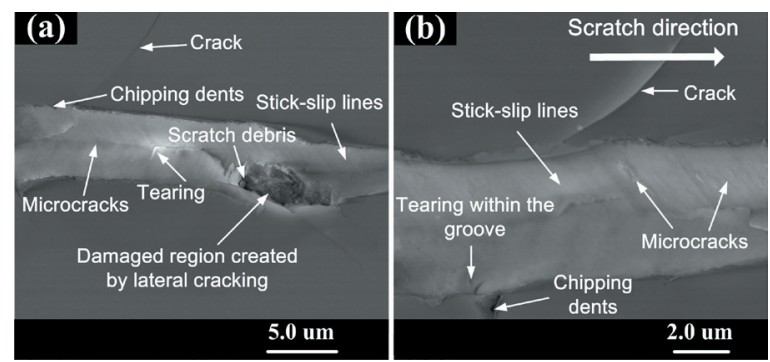

Fig. 6. Deformation features at the maximum load (approximately $200 \mathrm{mN}$ ) induced with scratch velocities of 4 and $8 \mu \mathrm{m} / \mathrm{s}$; a) scratch velocity is $4 \mu \mathrm{m} / \mathrm{s}$, b) scratch velocity is $8 \mu \mathrm{m} / \mathrm{s}$

Fig. 6 shows that brittle fracture regions are seen around the groove for a scratch velocity of $4 \mu \mathrm{m} / \mathrm{s}$, but not for a scratch velocity of $8 \mu \mathrm{m} / \mathrm{s}$ (Fig. 6b). Plastic and brittle deformation features are observed in and around the scratch grooves for scratch velocities of 4 and $8 \mu \mathrm{m} / \mathrm{s}$, and they are similar to the deformation features of the scratch grooves (as shown in Figs. 3 and 4) for scratch velocities of 2 and $16 \mu \mathrm{m} / \mathrm{s}$ as analysed in detail in the previous section.

Comparison analysis of the deformation features of the scratch grooves induced with different scratch velocities reveals that the scratch velocity affects the material removal features of the C-plane sapphire, i.e. a higher scratch velocity leads to a higher proportion of plastic deformation during the scratch process, which is very consistent with the surface depth profiles for the different scratch velocities (see Fig. 3). It is thus inferred that better processing performance can be achieved with an increase in cutting velocity, which is analogous to the scratch velocity, in the surface processing of sapphire and other brittle materials.

\section{DISCUSSION}

To understand the mechanism of different deformation features of the sapphire sample during the scratch process with different scratch velocities, the effects of scratch velocity on strain rate and hardness and the strain rate sensitivity as scratch velocity increases are addressed in the following section.

According to its definition, the strain rate $(\dot{\varepsilon})$ can be determined from the scratch velocity $(v)$ using the scratch depth $(h)$ in the plastic deformation stage of the sapphire sample, expressed as:

$$
\dot{\varepsilon}=\frac{v}{h} .
$$

Fig. 7 shows the effects of scratch velocity on strain rate under different scratch loads. It can be seen that the strain rate increases with increasing scratch velocity. Increasing the scratch load will have a negative influence on strain rate.

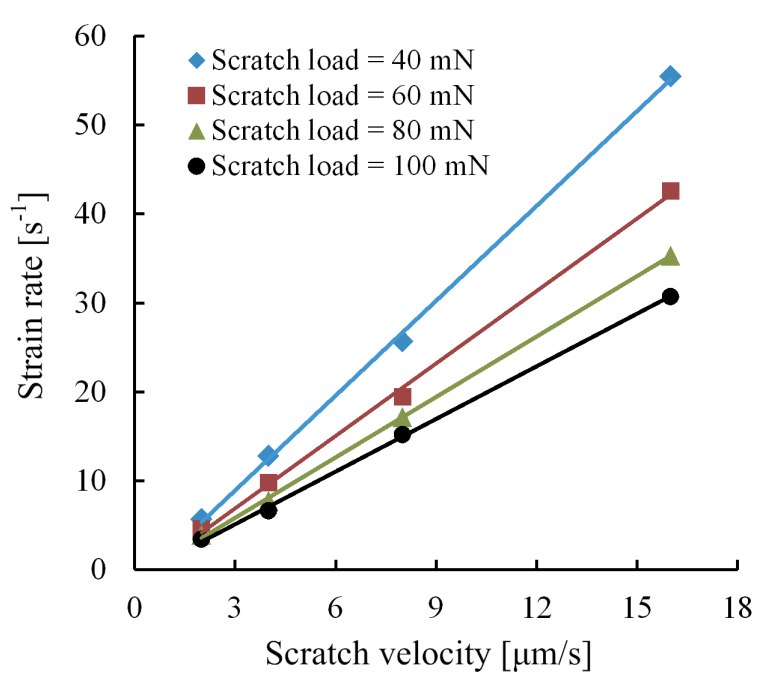

Fig. 7. Effects of scratch velocity on strain rate

Fig. 8 shows the effects of scratch velocity on hardness at lower loads where plastic deformation occurs without fracture. The calculation formula of hardness $(H)$ is expressed as: 


$$
H=\frac{P}{A},
$$

where $\mathrm{P}$ is the scratch load and $\mathrm{A}$ is the projected area of contact surface between the indenter and the workpiece, which can be determined by scratch depth $(h)$ in this study. It can be seen that hardness increases as scratch velocity increases. Increasing scratch load will have a negative effect on hardness.

According to the computed strain rate and hardness, the strain-rate sensitivity $(m)$ can be obtained by the following equation:

$$
m=\frac{\partial(\ln H)}{\partial(\ln \dot{\varepsilon})} .
$$

Fig. 9 presents the strain-rate sensitivity as scratch velocity increases. It shows that the strain-rate sensitivity is positive with increasing scratch velocity.

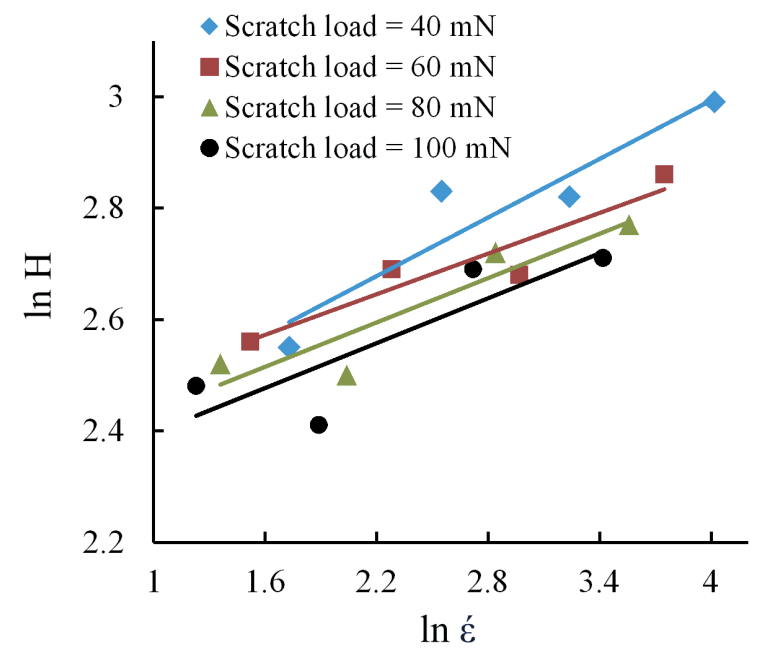

Fig. 9. Strain-rate sensitivity as scratch velocity increases

Existing research has shown that, due to increasing strain rate, the dynamic hardness from the dynamic indentation is greater than the static hardness for the C-plane sapphire, and dynamic indentation can effectively shorten the indentation-induced crack length relative to the crack length for static indentation [26] and [27]. In this study, all the above indicates that the scratch depth decreases with increasing scratch velocity, which infers an increase in hardness and strain rate. In other words, increasing scratch velocity will influence the mechanical properties of the sapphire sample, thus increasing the hardness, and will effectively restrain the occurence and growth of cracks; this leads to fewer and smaller cracks, and the plastic deformation is thus more comparable to the lower scratch velocity.

\section{CONCLUSIONS}

Nanoscratch experiments were conducted on a (0001) C-plane sapphire at scratch velocities of 2, 4, 8, and $16 \mu \mathrm{m} / \mathrm{s}$. Surface depth profiles recorded with the test system and deformation features observed by SEM for the different scratch velocities are discussed in this study. The residual stress features of the deformation zones in the scratch groove were observed by Raman spectroscopy to clarify the material removal mechanism of sapphire. The following conclusions are drawn.

(1) The surface depth profiles and microstructure observations made by SEM show that scratch depth and width increase with an increase in applied load.

(2) Deformation in each scratch process can be described as plastic deformation, plastic deformation with an increase in scratch depth and the appearance of microcracks, and brittle deformation with the emergence of chipping dents and damaged regions.

(3) Raman spectra obtained with a micro-Raman spectrometer show Raman peaks at lower wave numbers within the scratch groove compared to the ones collected outside the groove. It is inferred that tensile stress is present within the scratch groove during scratching, leading to the plastic deformation of the sapphire during scratching.

(4) Comparative studies of the surface depth profiles and scratch groove features induced with different scratch velocities reveal that the scratch velocity has distinct effects on the deformation features of C-plane sapphire. With increases in the scratch velocity, the surface depth profiles show that the critical load and depth increase and the scratch groove features show more slip lines and less chipping dents, implying that a higher scratch velocity leads to a higher proportion of plastic deformation in the scratching of C-plane sapphire.

(5) Examination of the mechanism of different deformation features for different scratch velocities shows that increasing scratch velocity can improve the strain rate and hardness, and can effectively restrain the occurence and growth of cracks, which leads to fewer and smaller cracks, and thus the plastic deformation observed is more comparable to that seen at a lower scratch velocity.

\section{ACKNOWLEDGMENTS}

This research was financially supported by the National Natural Science Foundation of China (Grant No. 50975153) and the State Key Laboratory 
of Tribology Foundation of China (Grant No. SKLT11C7).

\section{REFERENCES}

[1] Huang, L., Bonifacio, C., Song, D., Benthem, K.V., Mukherjee, A.K., Schoenung, J.M. (2011). Investigation into the microstructure evolution caused by nanoscratch-induced room temperature deformation in M-plane sapphire. Acta Materialia, vol. 59, no. 13, p. 5181-5193, DOI:10.1016/j.actamat.2011.04.054.

[2] Xu, W.H., Lu, X.C., Pa,n G.S., Lei, Y.Z., Luo, J.B. (2010). Ultrasonic flexural vibration assisted chemical mechanical polishing for sapphire substrate. Applied Surface Science, vol. 256, no. 12, p. 3936-3940, DOI:10.1016/j.apsusc.2010.01.053.

[3] Mao, W.G., Shen, Y.G., Lu, C. (2011). Nanoscale elastic-plastic deformation and stress distributions of the C plane of sapphire single crystal during nanoindentation. Journal of the European Ceramic Society, vol. 31, no. 10, p. 1865-1871, DOI:10.1016/j. jeurceramsoc.2011.04.012.

[4] Haney, E. J., Subhash, G. (2011). Analysis of interacting cracks due to sequential indentations on sapphire. Acta Materialia, vol. 59, no. 9, p. 3528-3536, DOI:10.1016/j. actamat.2011.02.026.

[5] Nakagawa, N., Waku, Y., Wakamoto, T. (2000). A new unidirectional solidified ceramic eutectic with high strength at high temperature. Materials and Manufacturing Processes, vol. 15, no. 5, p. 709-725, DOI:10.1080/10426910008913015.

[6] Vodenitcharova, T., Zhang, L.C., Zarudi, I., Yin, Y., Domyo, H., Ho, T., Sato, M. (2007). The effect of anisotropy on the deformation and fracture of sapphire wafers subjected to thermal shocks. Journal of Materials Processing Technology, vol. 194, no. 1-3, p. 52-62, DOI:10.1016/j.jmatprotec.2007.03.125.

[7] Zhang, Z.F., Yan, W.X., Zhang, L.L., Liu, W.L., Song, Z.T. (2011). Effect of mechanical process parameters on friction behavior and material removal during sapphire chemical mechanical polishing. Microelectronic Engineering, vol. 88, no. 9, p. 30203023, DOI:10.1016/j.mee.2011.04.068.

[8] Sidpara, A., Das, M., Jain, V.K. (2009). Rheological characterization of magnetorheological finishing fluid. Materials and Manufacturing Processes, vol. 24, no. 12, p. 1467-1478, DOI:10.1080/10426910903367410.

[9] Li, Y., Jie, W.Q., Gao, H., Kang, R.K. (2012). A new high-efficiency and low-damage polishing process of $\mathrm{HgCdTe}$ wafer. Materials and Manufacturing Processes, vol. 27, no. 2, p. 229-232, DOI:10.1080/104 26914.2011.566661.

[10] Zhu, H.L., Tessaroto, L.A., Sabia, R., Greenhut, V.A., Smith, M., Niesz, D.E. (2004). Chemical mechanical polishing (CMP) anisotropy in sapphire. Applied Surface Science, vol. 236, no. 1-4, p. 120-130, DOI:10.1016/j.apsusc.2004.04.027.
[11] Arif, M., Rahman, M., Yoke San, W. (2011). Analytical model to determine the critical feed per edge for ductile-brittle transition in milling process of brittle materials. International Journal of Machine Tools and Manufacture, vol. 51, no. 3, p. 170-181, DOI:10.1016/j. ijmachtools.2010.12.003.

[12] Liu, K., Li, X., Liang, S. (2007). The mechanism of ductile chip formation in cutting of brittle materials. The International Journal of Advanced Manufacturing Technology, vol. 33, no. 9, p. 875-884, DOI:10.1007/ s00170-006-0531-5.

[13] Chen, M.J., Zhao, Q.L., Dong, S., Li, D. (2005). The critical conditions of brittle-ductile transition and the factors influencing the surface quality of brittle materials in ultra-precision grinding. Journal of Materials Processing Technology, vol. 168, no. 1, p. 75-82, DOI:10.1016/j.jmatprotec.2004.11.002.

[14] Fang, F.Z., Chen, L.J. (2000). Ultra-precision cutting for ZKN7 glass. CIRP Annals-Manufacturing Technology, vol. 49, no. 1, p. 17-20, DOI:10.1016/ S0007-8506(07)62887-X.

[15] Pei, Z.J., Ferreira, P.M. (1999). An experimental investigation of rotary ultrasonic face milling. International Journal of Machine Tools and Manufacture, vol. 39, no. 8, p. 1327-1344, DOI:10.1016/S0890-6955(98)00093-5.

[16] Giridhar, D., Vijayaraghavan, L., Krishnamurthy, R. (2010). Micro-grooving studies on alumina ceramic material. Materials and Manufacturing Processes, vol. 25, no. 10, p. 1148-1159, DOI:10.1080/10426914.201 0.502952 .

[17] Huang, L., Lu, J., Xu, K. (2004). Elasto-plastic deformation and fracture mechanism of a diamondlike carbon film deposited on a Ti-6Al-4V substrate in nano-scratch test. Thin Solid Films, vol. 466, no. 1-2, p. 175-182, DOI:10.1016/j.tsf.2004.03.026.

[18] Huang, L.Y., Zhao, J.W., Xu, K.W., Lu, J. (2002). A new method for evaluating the scratch resistance of diamond-like carbon films by the nano-scratch technique. Diamond and Related Materials, vol. 11, no. 7, p. 1454-1459, DOI:10.1016/S0925-9635(02)000456.

[19] Subhash, G., Bandyo, R. (2005). A new scratch resistance measure for structural ceramics. Journal of the American Ceramic Society, vol. 88, no. 4, p. 918925, DOI:10.1111/j.1551-2916.2005.00181.x.

[20] Pogrebnyak, A.D., Beresnev, V.M., Kaverina, A.S., Kolesnikov, D.A., Yakushchenko, I.V., Ilyashenko, M.V., Makhmudov, N.A. (2012). Adhesive strength and physical, mechanical, and triboengineering properties of nano- and microstructural $\mathrm{Al} 2 \mathrm{O} 3$ coatings. Journal of Friction and Wear, vol. 33, no. 3, pp. 195-202, DOI:10.3103/S1068366612030087.

[21] Pogrebnyak, A.D., Beresnev V.M., Kaverina A.S., Kolesnikov D.A., Yakushchenko I.V., Ilyashenko M.V., Makhmudov N.A. (2012). Structure, morphology, physical and mechanical properties of nano- and microstructured coatings of $\mathrm{Al} 2 \mathrm{O} 3$ and $\mathrm{ZrO} 2$. Physics 
and Chemistry of Material Treatment, vol. 46, no. 5, p.18-25.

[22] Yao, W.L., Liu, J., Holland, T.B., Huang, L., Xiong, Y.H., Schoenung, J.M., Mukherjee, A.K. (2011). Grain size dependence of fracture toughness for fine grained alumina. Scripta Materialia, vol. 65, no. 2, p. 143-146, DOI:10.1016/j.scriptamat.2011.03.032.

[23] Klecka, M., Subhash, G. (2008). Grain size dependence of scratch-induced damage in alumina ceramics. Wear, vol. 265, no. 5-6, p. 612-619, DOI:10.1016/j. wear.2007.12.012.

[24] Ghosh, D., Subhash, G., Radhakrishnan, R., Sudarshan, T.S. (2008). Scratch-induced microplasticity and microcracking in zirconium diboride-silicon carbide composite. Acta Materialia, vol. 56, no. 13, p. 30113022, DOI:10.1016/j.actamat.2008.02.038.
[25] Ghosh, D., Subhash, G., Orlovskaya, N. (2008). Measurement of scratch-induced residual stress within $\mathrm{SiC}$ grains in $\mathrm{ZrB} 2-\mathrm{SiC}$ composite using micro-Raman spectroscopy. Acta Materialia, vol. 56, no. 18, p. 53455354, DOI:10.1016/j.actamat.2008.07.031.

[26] Haney, E.J., Subhash, G. (2011). Static and dynamic indentation response of basal and prism plane sapphire. Journal of the European Ceramic Society, vol. 31, no. 9, p. 1713-1721, DOI:10.1016/j. jeurceramsoc.2011.03.006.

[27] Klecka, M.A., Subhash, G. (2010). Rate-dependent indentation response of structural ceramics. Journal of the American Ceramic Society, vol. 93, no. 8, p. 23772383, DOI:10.1111/j.1551-2916.2010.03729.x. 